\title{
Adaption of Buildings Shape with Renewable Energy Consumption
}

\section{Badri Gorgiladze*}

Laboratory of Architectural Physics and Multimedia Design at Faculty of Architecture, Urban planning and Design of Georgian Technical University, 77 Kostava Str., 0160, Tbilisi, Georgia

\section{Gocha Mikiashvili}

International Design School of Georgian Technical University, 77 Kostava Str., 0160, Tbilisi, Georgia

\section{Nino Imnadze}

Faculty of Architecture, Urban planning and Design of Georgian Technical University,

77 Kostava Str., 0160, Tbilisi, Georgia

${ }^{*}$ Corresponding author: b.gorgiladze@gtu.ge

\section{Гrossef http://dx.doi.org/10.5755/j01.sace.26.1.23080}

The presented research aims to advance green energy consumption by integration of energy conversion schemes into buildings, as an inherent part of architectural construction. Realization of such tasks implies variation and adjustment of external shapes of buildings. Particular solutions depend on the chosen types of renewable energy sources, geographic location, and environmental conditions.

The novelty of suggested solutions is based on the principle of preliminary crowding of solar radiation, but against known analogs concentration of light by mirrors here used not for achieving of high amplitudes, but for diurnal equalization of an energy conversion process.

Autodesk software products have been used for adjustment of conceptual schemes, including the models of buildings shaped as right circular, or elliptic, cylindrical reflectors. The basic evaluation carried out for the North Temperate Zone.

Obtained results confirm that integration of local energy converters and appropriate modification of external shapes of buildings is more flexible and efficient than the application of centralized solar plants, because of their inexpensiveness and harmonization of beauty and energy efficiency. Application of static self-regulation of illuminance provides a high level of reliability and simplicity in exploitation. Suggested principle provides stepwise promotion of sustainability because it implies not only a passive economy of energy dissipation but also the equipment of architectural objects with inherent modules for active generation of renewable energy. Further development of such energy sourcing schemes is related also with the advancement of general safety (lowering of hazardous voltage) by the transition from common Electrical grid to adaptive local systems.

Keywords: sustainable, renewable, photovoltaic, energy, efficiency.

Main novelty of suggested approach is the task to integrate energy conversion modules into general architectural concept, transform them as an inherent part of green building, instead of their usage as outboard appliance on roofs and/or walls. One of kernel point for realization of such tasks implies variation and adjustment of external shapes of buildings. Certain solution depends on chosen types of renewable energy sources and geographic location, including environmental conditions.

Novelty of suggested schemes is based on the principle of preliminary crowding of solar radiation (and/or wind flow), but against known analogues concentration of light by mirrors here used not for achieving of high amplitudes, but for diurnal equalization of energy generation.

\section{Introduction}

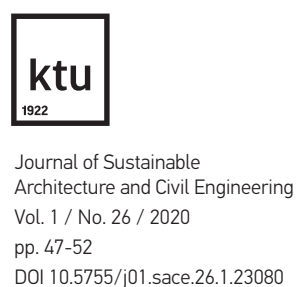


Below we try to argue flexibility and efficiency of local application of renewable resources against traditional usage of centralized solar plants and/or wind stations. However, to understand the essence of this idea, it is better to discuss the tasks separately, accordingly to the nature of appropriate physical processes.

Solar Radiation

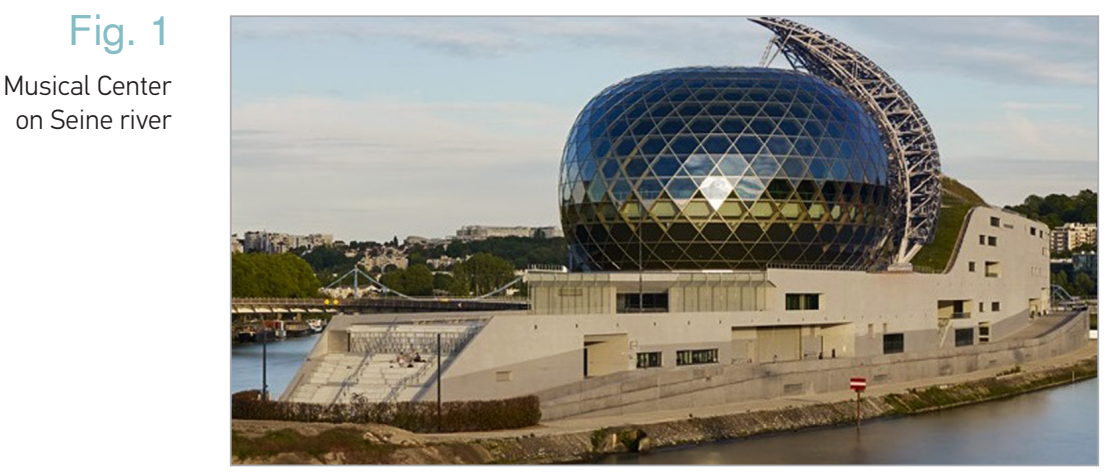

Fig. 2

Current-Voltage dependence from temperature for multi-crystalline typical Silicon Solar Cell de Gastines (Shigeru Ban 2017).
The advancement of semiconductor technologies used in solar cells caused a new reality (Valancius et al. 2018) when an electric energy supplying can be provided locally. Prices of photovoltaic panels, used with this purpose, decreased significantly. Moreover, the full sets of energy blocks from "Tesla" company also include the components for energy accumulation and possibility of their conjugation with standard power networks (https://www.tesla.com/en_EU/energy). Obviously, these innovative and quite actual technologies already have found reflection in modern architecture, and the best example is the Center for Music and Performing Arts "La Seine Musicale", built in western suburb of Paris. Project designed by architectural team of Shigeru Ban and Jean

The creative idea of architectural intent is related to the theme of "Solar wind". Structure reminding "Fantastic ship" (alike Sydney Opera House) built directly on an island in Seine River. The huge construction (mounting solar panels) looks like wind-blown sail and rotates around the central eggshaped body of the "ship" (Fig. 1). Auto regulation of the angle between panels and sun's rays (azimuth) performed by the rotation of this construction on the rails, around the central axis. At noon, when the

Sun reaches the highest point (altitude), the main workload comes on the panels adjacent to "Tip" (they have less surface area) while in the morning and evening, mainly contribute the wider lower sectors.

In general, the concentration of sun rays is important for solar energy application, as it performed in so called solar furnaces (Trombe et al. 1973), e.g. in France, or in Uzbekistan, but the crowding of solar radiation is not used for photovoltaic convertors, because their efficiency sharply falls (see Fig. 2) during overheating (Krauter and Ochs 2004). Generally solar panels have many specific features and for achieving of best results they should be taken into account, e.g. in a hot climate it is necessary to additionally install active coolers for this reason.

The principle proposed in the present paper provides the static self-regulation of receiver orientation against direction of sun rays by mirroring and choosing of building shapes. However, unlike the solar furnaces, the concentration of rays here performed just for equalizing of diurnal illuminance, not for reaching its high amplitude. Such statement of a task does not require special qual- 
ity of reflective surfaces and their exact positioning. This way incomparably reduces the final costs. Nowadays glass, as a material, is widely used in construction industry, because of its aesthetics and useful physical properties. Its surface is inert against harmful environmental factors. It is transparent in a visible area and so-called double-glazing provides with best insulation. Glass also has moreover resources. Expansion of glass constructions in modern cities causes abundance of scattered light background, what also can be used for different purposes.

Variations of glass-faced building shapes became a most popular in modern architecture. One of the core points is to gain maximal technical effectiveness along with the aesthetic beauty. We assume that more resource lies in the reflective properties of a glass surface. Fig. 3 shows vertically arranged multiple double glazing units' chain along the elliptical contour, which creates reflective surfaces on one horizontal layer (floor). Such reflective "belt" of windows in horizontal section has the shape of a sliced claw, diagonal of which is parallel to East-West geographic direction. Inner mirrors (constitute elliptic cylindrical collector) directed towards the South (in models destined for North temperate zone).

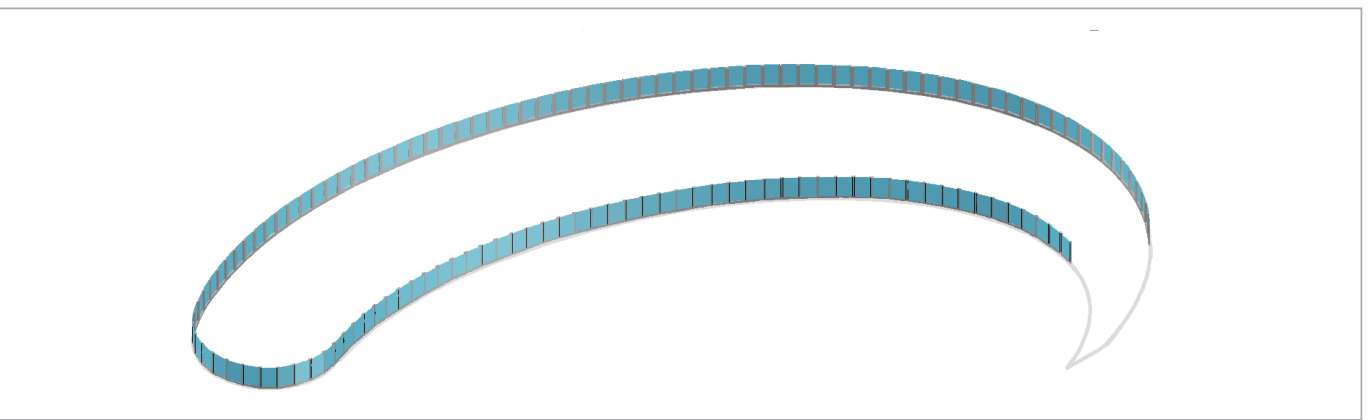

Fig. 3

The mirror's belt along one storey

During daylight, when the azimuth of the Sun is changed, only several part of solar rays (reflected from a few mirrors) fall onto one receiver mounted on narrow tower located in elliptic foci (doesn't shown on this drawing). Compensation of the height of the Sun (as well as the seasonal changes) self-regulated by daytime alternations of "active layers" (floors). It means that during daylight, at any moment of time, sunrays fall onto one receiver only from a few mirrors. Correction of mirrors arrangement obeys the principle to supply the solar panels with maximal illuminance in the morning and the evening. At noon contrary radiation flow on cells decreases, due to increase of an incident angle. Thus panels are optimally lightened and protected from overheating.

Efficiency of this scheme lie in the following:

Instead of installation of many expensive solar panels, we use the usual glass surface of a building (windows and/or other glazing superficial segments) as a reflector directing light on smaller amount of panels. We do not add any material or coating, we just planning beforehand azimuthal orientation of windows (they remain vertical). So additional cost does not arise.

Thus, the number of solar panels are optimized and mounted on separately arranged tower. Accumulators and other accessories also placed in the same tower, at a distance from main building, so its safety remains uncompromised. Drawing on Fig. 4 shows the simplified part of a building model designed by application of AutoCad.

The forms presented in a given scale are perceived as smooth, although after proper magnification it becomes visible that all the mirrors (glass wall, or window) are absolutely flat, in fact.

Despite the choosing of ellipse shape for the base contour, the orientation of each window is specified with the "Solar Angle Calculator" tool, integrated in AutoCad. Solar panels' holding tower built along 


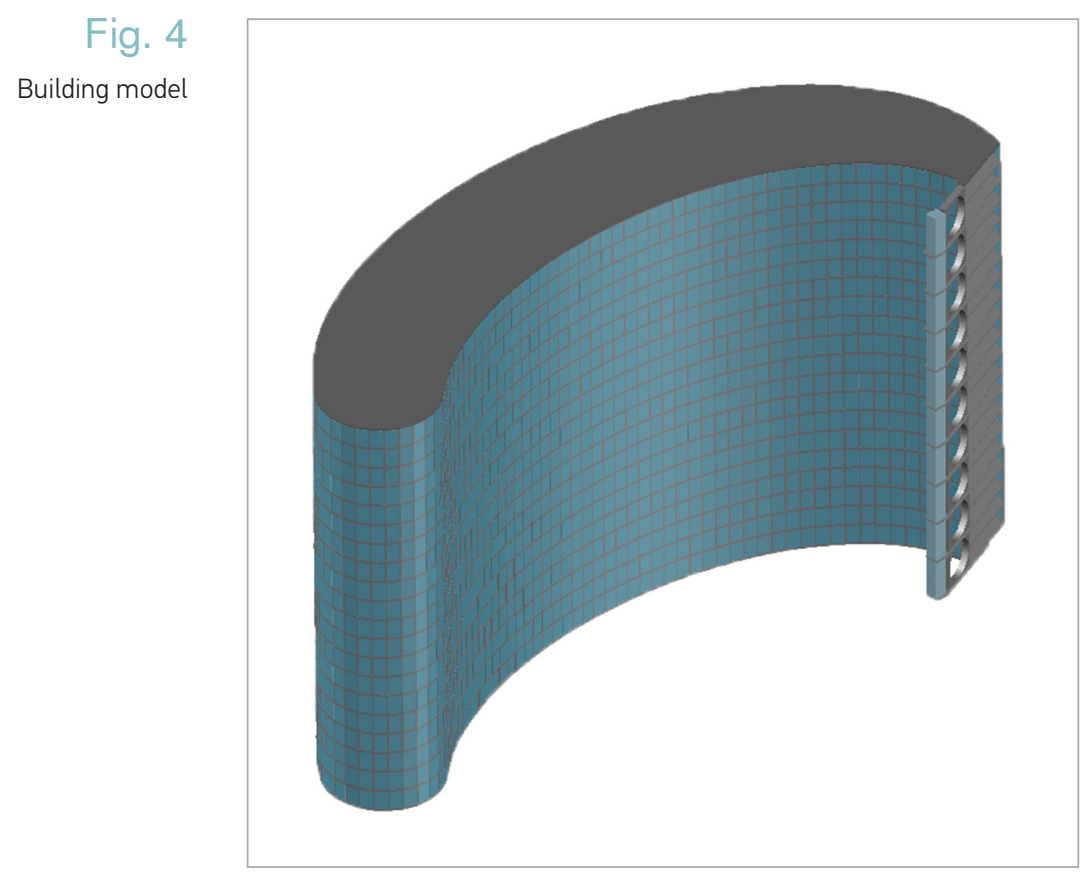

one focal axis in given model, because it is enough for illustration of suggested principle. More effective focusing of solar energy will be possible by the mirrors arranged along cylindrical surface, but this would be justified in colder climatic conditions or in a case when the solar energy directly converted in a heat (or at a joint application of this technique). It means, that choosing of the building shape generally allows us to get the substantial improvement of energy efficiency. The full shape, shown on Fig. 4, is conditional, because just part of South walls work as a reflector, the rest body of the building can be designed with any other

architectural concept. There are the areas on the South face (especially on lower floors) contribution of which is minimal and accordingly, here it is possible to replace glass with other material. For illustration of benefits associated with the application of suggested principle, it can be compared with so-called passive water heaters (Morsink-Georgali et al. 2017). In multi-storey urban-type buildings, usually they are mounted on the roofs and mainly are available only for the residents of upper-floors. Such an equipment needs the special thermally insulated case, glass roof and other components and only expensive models contain the reflectors of solar rays. As an alternative version, we can discuss the scheme, working for the whole building. The main component - solar energy concentrator (reflector) emerged practically free-of-charge by initial positioning of windows and other glass surfaces. The solar radiation reflected from it falls on narrow glass tower, where the cheapest black plastic pipes used as water heater and conductor. Overall coast of such integrated system is smaller than sum of separate standard solar energy water heaters.

Initial choosing of building shapes in such manner is reasonable even if not intended immediate full completion of architecture with autonomous energy system, because it is so flexible that enables late consummation and/or replacement of converters working in different modes and/or combinations.

The intervention into city environment with any new building frequently can cause certain disturbance in adjoining spaces, but our innovation possess advantage even above usual rectangular buildings. The matter is that suggested shapes have especial property to collect the reflected daylight in a focal plane where receivers of energy are located. By this reason its undesirable influence on surrounding buildings is absolutely excluded. I.e. Application of the suggested principle even theoretically cannot cause discomfort for people in neighboring location.

Usage of wind as a renewable energy source obviously has longer history, than the solar panels. Nowadays the total capacity of wind energy-aggregates amounts to half terawatt. The wind on the Earth also related to the absorption of sun's radiation and its application also complicated by variability of wind direction and speed. Therefore, it is necessary to provide auto-correction 
of generator's wings' orientation. Theoretically it is also possible to regulate the wind flow (like solar energy concentration) and such schemes have already appeared in practice (Allaei and Andreopoulos 2014).

In the proposed concept, where the external shape of a building has the leading importance, the compensation of obstructive variable parameters is realized by stationary constructions, not with special dynamic, so called, "Tracking" systems. The optical properties of 3D construction shown on the drawing 4, provide such possibility of auto correction, moreover it turned out that such building, having claw-like section, possesses also the ability to regulate the wind flow. It can be said, symbolically, that the shape of a building can perform the function of a sail, but a building will not be moved, its shape just collect the wind flow, kinetic energy of which will be converted into electricity. Drawing 4 shows cylinder-shaped sections, where the wind standard aggregates can be arranged, but significant increase of their efficiency (adjustment to the weak wind) is possible by the special constructions having vertical spin axis and semi-cylindrical wings.

The profitable joint application of the solar and wind energies, under proposed scheme, is possible in such geographic locations (e.g. in ravines) where the wind annual dominant direction coincides with the scheme requirements. In any case, the buildings with similar external shape cause a local turbulence and suppress the power of wind in a city. Interrelation between external shape of buildings with their energy saving characteristics became actual even without involving of power-producing modules (Barea and Gelard 2018, Akadiri et al. 2012, Raof 2017).

The main component of suggested design, local system for solar energy conversion, equipped with the power accumulation module, destined for DC - Direct current. In due time, at the beginning of Electrical grid establishment (interconnected network for delivering electricity from producers to consumers) priority was given to AC (Alternating current), because it makes easier to regulate energy loses during transmission of power. However, DC is more profitable at a local generation of electricity, because direct current machines and generators are more compact, and have better coefficient of efficiency. Thus, instead of AC generators currently used in so-called wind stations, local wind energy conversion systems must be based on DC generators. Such a solution especially justified when the accumulators' module already exists, e.g. at the joint application of wind and solar energy convertors. In this case, additional expenses limited just by the price of wind powered generators. The automatic operation of the whole system can be performed by quite simple controller. The power generated by such system used directly, without any losses. Accumulators are supplied for charging only during excessive generation, what maximally increases coefficient of efficiency for the whole system.

Taking into account the general development of modern semi-conductor industry, it can be said that further application of 220 volt AC networks it is unreasonable. High voltage is hazardous not only as shocking factor, more often it causes conflagration (caused by e.g. electrical breakdown). It will be better to supply home devices by DC lover 50 volt. Under such standard, the majority of modern household electric appliances disengage from disadvantageous "voltage lowering transformers" and "rectifier" modules. Such an alteration leads to decreasing of home appliances costs and advancement of their safety. In fact, such global technological tasks do not belong to the field of architecture, although if these issues will be ignored by architects, it will be impossible to achieve such a scale innovation.

One of the main challenges of XXI century is the rehabilitation of environment and saving of natural resources. We think that advancement of renewable energy consumption by adaption of the buildings shapes encourage realization of its tasks and lead to second stage of sustainable development, which can be characterized as "active green architecture".

\section{Systemic Characteristics and Conclusions}




\section{References}

Akadiri P.O., Ezekiel A., Olomolaiye Ch., Olomolaiye P.O. Design of A Sustainable Building: A Conceptual Framework for Implementing Sustainability in the Building Sector. Buildings. V.2, Issue 2. 2012. https://www.mdpi.com/2075-5309/2/2/126. https://doi.org/10.3390/buildings2020126

Allaei D., Andreopoulos Y. INVELOX. Description of a new concept in wind power and its performance evaluation. Energy 69.2014. https://www.sciencedirect.com/science/article/pii/S0360544214002837. https://doi.org/10.1016/j.energy.2014.03.021

Esteves A., Esteves M.J., Mercado M.V., Barea G., Gelard D. Building Shape that Promotes Sustainable Architecture. Evaluation of the Indicative Factors and Its Relation with the Construction Costs. Architecture Research. 8(4). 2018. http://article.sapub. org/10.5923.j.arch.20180804.01.html. http://article. sapub.org/10.5923.j.arch.20180804.01.html

Krauter S., Ochs F. Integrated solar home system. Renewable Energy 29 (2004) 153-164. https://www. researchgate.net/publication/4078571_Integrated_solar_home_system. https://doi.org/10.1016/ S0960-1481(03)00190-3

Morsink-Georgali F.Z., Kylili A., Fokaides P.A. Life Cycle Assessment of Flat Plate Solar Thermal Col- lectors. Journal of Sustainable Architecture and Civil Engineering (JSACE). V.21, No 4, 2017. http://sace. ktu.lt/index.php/DAS/article/view/18299. https:// doi.org/10.5755/j01.sace.21.4.18299

Raof B. The correlation between building shape and building energy performance. Int. J. of Adv. Res. 5 (5). 2017. http://www.journalijar.com/ article/17383/the-correlation-between-building-shape-and-building-energy-performance-. https://doi.org/10.21474/IJAR01/4145

Shigeru Ban Architects. La Seine Musicale. e_journal ArchDaily. 28 June, 2017. www.archdaily.com

Trombe F., Le Phat Vinh A. Thousand kW solar furnace, built by the National Center of Scientific Research, in Odeillo (France). Solar Energy. V.15, Issue 1, 1973, P. 57-61. https://www.sciencedirect.com/ science/article/pii/0038092X73900066. https://doi. org/10.1016/0038-092X(73)90006-6

Valancius R., Singh A., Mutiari A., Alexander C., De La Cruz D.A., Del Pozo F.E. Jr. Solar Photovoltaic Systems in the Built Environment: Today Trends and Future Challenges. Journal of Sustainable Architecture and Civil Engineering (JSACE). V. 23, No 2, 2018. http:// sace.ktu.lt/index.php/DAS/article/view/21268. https://doi.org/10.5755/j01.sace.23.2.21268

\section{About the Authors}

\section{BADRI GORGILADZE \\ Head of Laboratory \\ Architectural Physics and Multimedia Design at Faculty of Architecture, Urban planning and Design of Georgian Technical University}

\section{Main research area}

Architecture, Physics, Informatics, Computer modeling.

\section{Address}

77 Kostava Str., 0160,

Tbilisi, Georgia

Tel. (+99532) 2233293,

Mob. (+99555) 195793

E-mail: b.gorgiladze@gtu.ge

\section{GOCHA MIKIASHVILI}

Professor

International Design School of Georgian Technical University

\section{Main research area}

Architecture.

\section{Address}

77 Kostava Str., 0160, Tbilisi, Georgia

Tel. (+99532) 2233895,

Mob. (+99599) 503281

E-mail: gochamikia@yahoo.com

\section{NINO IMNADZE}

\section{Professor}

Dean of Faculty of Architecture

Urban planning and Design of

Georgian Technical University

Main research area

Architecture, Urban planning.

\section{Address}

77 Kostava Str., 0160 ,

Tbilisi, Georgia

Tel. (+99532) 2227777,

Mob. (+99599) 223747

E-mail:n.imnadze@gtu.ge 